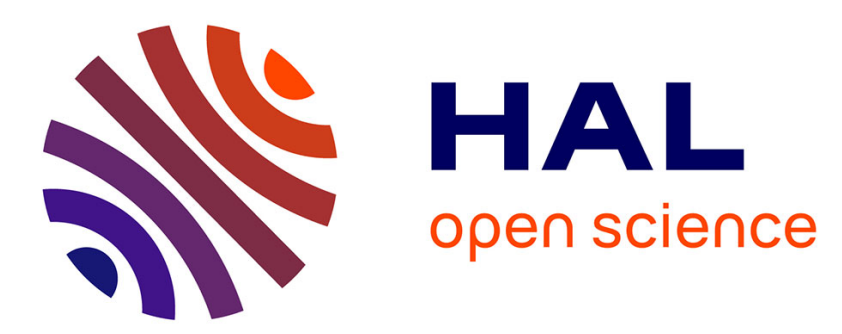

\title{
Modeling the precipitation processes and the formation of hierarchical microstructures in a single crystal high entropy superalloy
}

Stéphane Gorsse, Yung-Ta Chen, Wei-Che Hsu, Hideyuki Murakami, An-Chou Yeh

\section{To cite this version:}

Stéphane Gorsse, Yung-Ta Chen, Wei-Che Hsu, Hideyuki Murakami, An-Chou Yeh. Modeling the precipitation processes and the formation of hierarchical microstructures in a single crystal high entropy superalloy. Scripta Materialia, 2021, 193, pp.147-152. 10.1016/j.scriptamat.2020.11.002 . hal03010103

\section{HAL Id: hal-03010103 https://hal.science/hal-03010103}

Submitted on 27 Nov 2020

HAL is a multi-disciplinary open access archive for the deposit and dissemination of scientific research documents, whether they are published or not. The documents may come from teaching and research institutions in France or abroad, or from public or private research centers.
L'archive ouverte pluridisciplinaire HAL, est destinée au dépôt et à la diffusion de documents scientifiques de niveau recherche, publiés ou non, émanant des établissements d'enseignement et de recherche français ou étrangers, des laboratoires publics ou privés. 


\title{
Modeling the precipitation processes and the formation of
}

\section{hierarchical microstructures in a single crystal high entropy}

\section{superalloys}

\author{
Stéphane Gorsse ${ }^{1,2,{ }^{*}}$, Yung-Ta Chen ${ }^{2,3}$, Wei-Che Hsu ${ }^{2,3}$, \\ Hideyuki Murakami ${ }^{4,5}$, An-Chou Yeh ${ }^{2,3, *}$
}

${ }^{1}$ CNRS, Univ. Bordeaux, Bordeaux INP, ICMCB, UMR 5026, F-33600 Pessac, France.

${ }^{2}$ Department of Materials Science and Engineering, National Tsing Hua University, 101, Sec. 2, KuangFu Road, Hsinchu, 30013 Taiwan, ROC.

${ }^{3}$ High Entropy Materials Center, National Tsing Hua University, 101, Sec. 2, Kuang-Fu 10 Road, Hsinchu, 30013 Taiwan, ROC.

${ }^{4}$ Research Center for Structural Materials, National Institute for Materials Science, 1-2-1 Sengen, Tsukuba, 305-0047 Japan.

${ }^{5}$ Department of Nanoscience and Nanoengineering, Waseda University, 3-4-1 Okubo, Shinjuku, Tokyo 169-8555, Japan.

\begin{abstract}
Although superior high temperature tensile yield strength of high entropy superalloys (HESAs) arises from their hierarchical microstructure, the precipitation processes driving its formation remains unclear. In the present study, we analyze the kinetics of $\gamma^{\prime}$ - and $\gamma$ - precipitations by treating the concurrent nucleation, growth and coarsening using common computational thermodynamic and kinetic tools to simulate the microstructure genesis and evolution in HESA during thermal treatments. The ability of the simulations to reproduce the experimentally observed microstructure parameters is evaluated. Temperature-time-transformation (TTT) diagrams are calculated to serve as guidelines for further optimization of the hierarchical microstructure of HESAs.
\end{abstract}


Ni-based superalloys have been the best answer so far to the demand for high-temperature structural materials in modern gas turbine engines used in the aerospace and energy industries. This demand-driven material requirement mainly raised from the economic advantages of increased efficiency at higher operative temperature. Nowadays, ecologic imperative on cutting down in $\mathrm{CO}_{2}$ emissions of the aircraft sector and gas-fired power plants represents a further strong incentive for the research and development of new alloys with even better high-temperature capability than $\mathrm{Ni}$ based superalloys (i.e. enhanced resistances to high-temperature creep and high-temperature oxidation).

Excellent high-temperature mechanical properties of Ni-based superalloys result from their $\gamma-\gamma^{\prime}$ microstructure, i.e. $\mathrm{Ni}_{3} \mathrm{Al}$-based precipitates $\left(\gamma^{\prime}\right)$ with an $\mathrm{L}_{2}$-ordered structure coherently embedded in a disordered $\gamma$ matrix phase with a face-centered cubic (FCC-A1) structure [1]. Because of its great success in Ni-superalloys, the $\gamma-\gamma^{\prime}\left(A 1+L 1_{2}\right)$ microstructure is regarded as a template for the development of two new classes of high-temperature alloys whose underlying concepts have been discussed in recent papers, i.e. high entropy superalloys (HESAs) [2-4] and refractory superalloys (RSAs) $[5,6]$. In brief, by shifting from the center of hyper-dimensional composition space, HESAs fill the compositional gap between equimolar high entropy alloys (HEAs) and Ni-based superalloys, and RSAs are $B C C(A 2)$-based refractory complex concentrated alloys (RCCAs) with B2-ordered phase. While the transformation pathways responsible for forming the $A 2+B 2$ microstructure are unknown and that available thermodynamic databases do not include or fail to correctly describe the B2 phase in refractory systems, the development of HESAs could benefit from well-established Ni-based thermodynamic and kinetics CALPHAD databases.

The general intention of this article is to assess the agreement between observations of the $\gamma-\gamma^{\prime}$ microstructure in HESA with CALPHAD calculations of the precipitation process using common computational thermodynamic and available databases. For that, we will rely on the detailed information on the precipitation kinetics in one HESA recently published by Chen et al. [7]. Our interest in this HESA is spotted by the formation of a hierarchical microstructure comprising 
secondary $\gamma$ spherical particles formed inside primary $\gamma^{\prime}$ cuboid precipitates and its elevated temperature tensile yield strength which overcomes that of advanced superalloys such as the CMSX4 benchmark. Hierarchical microstructures are not specific to HESA, they were also observed in several aged Ni-based superalloys such as IN-738 [8], Mar-M200, IN-100 [9], and CMSX-4 [10], as well as in model $\gamma^{\prime}$ precipitation hardened ternary alloy such as Ni-Al-Ti [11,12], Ni-Si-Fe [13,14], Ni-Al-Fe [13], and Ni-Al-Si [15]. Their formation was first explained by H. F. Merrick [8] and Oblak [9] as the precipitation of $\gamma$ within $\gamma^{\prime}$ particles during aging. In the following, we present the results of the investigation on the precipitation kinetics and the predicted temperature-time-transformation (TTT) diagram for the phase separation of the $\gamma$ matrix and of $\gamma^{\prime}$ coherent precipitates causing the hierarchical $\gamma / \gamma^{\prime}$ two-phase microstructure in HESA.

In this work, the nucleation, growth and coarsening of precipitates during cooling and thermal treatments in HESA was treated using the Thermo-Calc Precipitation Module (TC-PRISMA) integrated into a programming workflow with TC- Python, the thermodynamic database TCNI9 and the kinetic database MOBNI5 from Thermo-Calc [16]. TCNI9 includes the assessed thermodynamic descriptions for all the ternary systems with Ni comprised in the present Ni-rich HESA. TC-PRISMA model is built on Langer-Schwartz theory [17] and the Kampmann-Wagner numerical approach [18]. The effects of interfaces on equilibrium solubilities of small particles are accounted for using the Gibbs-Thomson equation. The simulations of diffusion-controlled precipitation kinetics and temperature-timetransformation (TTT) diagrams for $\gamma$ and $\gamma^{\prime}$ in HESA were performed through the TC-Python Software Development Kit (SDK) allowing to couple TC-PRISMA with other numerical packages for data visualization.

The nominal composition of the HESA is listed in Table 1 [7]. Single crystal HESA samples were fabricated along [001] orientation by Bridgman method from Superalloys and High Temperature Materials Group in National Institute for Materials Science (NIMS), Japan. The as-cast samples were homogenized and solutioned at $1500 \mathrm{~K}$ for $20 \mathrm{~h}$ followed by air cooling to room temperature. After 
solution treatment, aging window (temperature and time space) for the formation of $\gamma$ particles inside the primary $\gamma^{\prime}$ precipitates were examined at $723,923,1023,1123$ or $1223 \mathrm{~K}$ for 20 hours, or at $1023 \mathrm{~K}$ for $10,20,50,100$ or 200 hours followed by water quench. The presence of nano-sized $\gamma$ particles were characterized by Scanning Electron Microscope (SEM: JEOL 7200F) with the samples prepared by grinding and electro-etching in $20 \% \mathrm{H}_{3} \mathrm{PO}_{4}+80 \% \mathrm{H}_{2} \mathrm{O}$ solution at $2.5 \mathrm{Volts}$. Based on the SEM images, the average radius and number densities of $\gamma$ particles were determined by NanoMeasurer software. Additional structural information was revealed by Transmission Electron Microscope (TEM: JEOL JEM-F200, $200 \mathrm{kV}$ ) with the thin foils prepared by twinjet polishing in the solution containing $10 \% \mathrm{HClO}_{4}+90 \% \mathrm{C}_{2} \mathrm{H}_{5} \mathrm{OH}$ under 30 Volts / $-30{ }^{\circ} \mathrm{C}$.

Figures 1a-b show the SEM image, the dark field TEM image and the corresponding electron diffraction pattern of single crystal HESA with the composition shown in Table 1, after homogenization and solutioning at $1500 \mathrm{~K}$ for $20 \mathrm{~h}$ followed by air cooling to room temperature according to the temperature profile shown in Figure $2 \mathbf{a}$. The microstructure consists of $\gamma^{\prime}$ precipitates, with a volume fraction of 0.68 , embedded in the $\gamma$ matrix. Superlattice diffraction pattern observed on the [001] zone axis indicates that these precipitates possess a $L 1_{2}$ structure. The $\gamma^{\prime}$ precipitates exhibit two different morphologies, i.e. large primary cuboids and small secondary spherical particles. The size of cuboid precipitates was taken as the radius of a circle with equivalent area. The estimate from image analysis gives $72 \mathrm{~nm}$ of equivalent radius for the primary $\gamma^{\prime}$ and 0.5 $\mathrm{nm}$ for the secondary $\gamma^{\prime}$. The chemical composition of the primary and secondary $\gamma^{\prime}$ precipitates formed after air cooling was investigated by atom probe tomography and listed in Table 1.

Table 2 summarizes the subsequent isothermal aging treatments performed on the air cooled HESA. Aging at $1023 \mathrm{~K}$ for $20 \mathrm{~h}$ followed by water quenching causes the precipitation of nano-sized $\gamma$ particles with spherical shape inside the $\gamma^{\prime}$ cuboidal primary precipitates, resulting in the formation of the hierarchical microstructure (Figs. 1c-g). No $\gamma$ particle is visible inside $\gamma^{\prime}$ for aging performed at $723,923,1123$ or $1223 \mathrm{~K}$. The precipitation of $\gamma$ inside $\gamma^{\prime}$ is already visible after $10 \mathrm{~h}$ at $1023 \mathrm{~K}$, while 
the $\gamma$ particles increase in size and decrease in number density during prolonged aging, to finally disappear after $200 \mathrm{~h}$. To compare observations and simulations, we converted the apparent particle radius, $r$, and number of particles per unit area, $N_{A}$, from 2D sections into $3 \mathrm{D}$ spheres of radius $R=4 r / \pi$ [19], and number density per unit volume, $N_{V}=N_{A} /(2 R)$ [20] (Table 3).

Transformation upon continuous cooling - The regularity of the microstructure shown in Figure 1a illustrates the morphological adaptation of the $\gamma^{\prime}$ precipitates inside the $\gamma$ matrix resulting from the interplay between coherency stresses (stress fields arising from coherency strains due to the lattice misfit between $\gamma$ and $\gamma^{\prime}$ ) and interfacial energy. To capture the genesis and evolution of this microstructure it is necessary to consider the elastic anisotropy of the $\gamma$ matrix, being known that the $<100>$ directions are less rigid than the $<110>$ and $<111>$ directions. Values of elastic constants $C_{11}=$ $250 \mathrm{GPa}, \mathrm{C}_{12}=160 \mathrm{GPa}$ and $\mathrm{C}_{44}=130 \mathrm{GPa}$ were taken from Wen et al. [21] who investigated one Nibased superalloy with a composition close to that of the present HESA composition. Interfacial energy between $\gamma^{\prime}$ and $\gamma$ was tuned by matching precipitate sizes measured by image analysis. The obtained value of $0.08 \mathrm{~J} / \mathrm{m}^{2}$ is similar with typical values found in Ni-based superalloys such as TMW4M3 and NIMONIC exhibiting high volume fraction of $\gamma^{\prime}$ phase (above 50\%) [22]. On the other hand, lower values of interfacial energy, about $0.02 \mathrm{~J} / \mathrm{m}^{2}$, is generally observed in $\mathrm{Ni}$-based superalloys with a low volume fraction of $\gamma^{\prime}$ precipitates such as in the Alloy 617 (about 6.4\%) [23]. This observation suggests a positive correlation between the $\gamma^{\prime} / \gamma$ interfacial energy and the volume fraction of $\gamma^{\prime}$ precipitation in $\mathrm{Ni}$-based superalloys.

Figure $\mathbf{2} \mathbf{b}$ shows the calculated particle size distribution and the cubic factor [24] of the $\gamma^{\prime}$ precipitates formed during continuous cooling from the solvus temperature according to the temperature profile in Figure $\mathbf{2 a}$. Upon cooling, while the primary $\gamma^{\prime}$ precipitates are growing, they undergo successive changes in shape from a spherical shape, when interfacial energy is predominant, to a cuboid morphology, when coherency energy dominates. The calculated radius of the primary and secondary precipitates is in good agreement with the measurements (Fig. 2b), and the 
simulation captures well the bimodal distribution of the precipitate's sizes according to two different morphologies.

Further insights into the precipitation process are provided by the calculated TTT diagram in Figure 3. In addition to the temperature-time combinations calculated for a volume fraction of $1 \%$ of $\gamma^{\prime}\left(\gamma^{\prime}\right.$ start curve), the predicted temporal evolution of the radius, volume fraction, and morphology of $\gamma^{\prime}$ precipitates are represented in the temperature-time space for both isothermal (aging) and nonisothermal (continuous cooling from the solvus temperature) treatments. According to calculations, the precipitation kinetic of $\gamma^{\prime}$ occurs very rapidly in HESA, at a slightly shorter timescale compared to most of the Ni-based superalloys. For example, the air cooling process of the CM247LC Ni-based superalloy results in $\gamma^{\prime}$ radius around $50 \mathrm{~nm}$ [25] while it is $72 \mathrm{~nm}$ in HESA after air cooling (note that in [7] the reported value of $143 \mathrm{~nm}$ represents the diameter of primary $\gamma^{\prime}$ while in the present paper we refer to the radius). The radius of $\gamma^{\prime}$ in the FGH98 Ni-based superalloys is about $40 \mathrm{~nm}$ after cooling from the solvus temperature at a rate of $10.8 \mathrm{~K} / \mathrm{s}$ [26], while in HESA the radius of $\gamma^{\prime}$ is twice larger $(72 \mathrm{~nm}$ ) for a cooling twice faster (about $20 \mathrm{~K} / \mathrm{s}$ between the solvus temperature and $1000 \mathrm{~K}$ ). The higher precipitation kinetics in HESA can be attributed to faster chemical diffusion due to less refractory contents than in conventional Ni-based superalloys. As shown in Figure 3, even quenching 100 times faster than air cooling cannot avoid crossing the $\gamma^{\prime}$ start curve; it takes only few seconds for $\gamma^{\prime}$ to precipitate and grow in HESA. This is also observed for conventional Ni-based superalloys such as CM247LC, for which fast quenching process, such as forced argon cooling, cannot avoid nucleation of $\gamma^{\prime}$ precipitates and result in a refinement of the precipitation structure (higher number density and smaller size of $\gamma^{\prime}$ particles) [25].

Hierarchical precipitation during aging - We find that $\gamma^{\prime}$ precipitates formed during air cooling are supersaturated in $\mathrm{Co}, \mathrm{Cr}$ and Fe (Table 1), therefore driving the formation of $\gamma$ particles inside $\gamma^{\prime}$ during aging at $1023 \mathrm{~K}$ (Table 2, Figures 1c-g). Figure 4 shows the calculated TTT diagram for the precipitation of $\gamma$ from $\gamma^{\prime}$ with composition measured by APT (Table 1), which was reported in 
previous work [7]. The $\gamma$ start and the $50 \%$ completion curves indicate that the precipitation of $\gamma$ inside $\gamma^{\prime}$ occurs at lower temperatures and with lower rates than for $\gamma^{\prime}$ from $\gamma$. The isothermal aging treatments applied to HESA after cooling (Table 2) are represented at the corresponding temperature-time coordinates. When the coordinate lies inside the $\gamma$ start curve, the experimental point is denoted by a circle whose radius is proportional to the calculated average radius of the $\gamma$ precipitates and the color indicates their number density, $N_{V}$. In contrast, when the aging falls outside the $\gamma$ start curve (i.e. in the supersaturated $\gamma^{\prime}$ region of the temperature-time space), it is shown as black diamond.

The assessment of the validity of the predictions presented in Figure 4 is done by comparing three features from the observations: (1) the occurrence or not of the phase separation (i.e. formation of the hierarchical microstructure), (2) the average size, and (3) the number density of the $\gamma$ particles inside $\gamma^{\prime}$ precipitates as a function of the temperature and time of the thermal treatments. Firstly, the calculated TTT diagram (Figure 4) reveals that the $723 \mathrm{~K} / 20 \mathrm{~h}$ and $1223 \mathrm{~K} / 20 \mathrm{~h}$ temperature-time coordinates remain in the metastable supersaturated $\gamma^{\prime}$ region which explains that phase separation is not experimentally observed. Even though $\gamma^{\prime}$ could eventually serves as a matrix for $\gamma$ precipitates for both these temperatures, at $1223 \mathrm{~K}$ there is not enough driving force while at $723 \mathrm{~K}$ there is a lack of atomic mobility for the precipitation to occur. By contrast, thermal treatments performed at 1023 $\mathrm{K}$ are located inside the $\gamma$ start curve where the kinetics are at the highest, which is consistent with the observations. At $923 \mathrm{~K} / 20 \mathrm{~h}$ and $1123 \mathrm{~K} / 20 \mathrm{~h}$, the results of the calculations give new insights about the absence of hierarchical structure for these temperature-time coordinates: at $923 \mathrm{~K} / 20 \mathrm{~h} \gamma$ precipitates are two small (less than $1 \mathrm{~nm}$ ) for SEM resolution, and at $1123 \mathrm{~K} / 20 \mathrm{~h} \gamma$ precipitates are too few (about $1 \gamma$ particle every $100 \gamma^{\prime}$ precipitates) to be caught during observation. Secondly, there is an overall good agreement between measured and calculated values for the radius of the $\gamma$ particles formed inside $\gamma^{\prime}$ precipitates after aging at $1023 \mathrm{~K}$. The deviation between observed and calculated values of the radius is less than $20 \%$. Thirdly, measured and predicted values of the number density of the $\gamma$ particles are of the same order of magnitude and follow the same decreasing 
trend with the duration of the thermal treatment, from about $10^{23}$ after $10 \mathrm{~h}$ for both, to $10^{20} \mathrm{~m}^{-3}$ and $10^{22} \mathrm{~m}^{-3}$ after $200 \mathrm{~h}$, respectively, for the experimental observation and the prediction. This assessment suggests that the present model based on TC-PRISMA, and operating the thermodynamic database TCNI9 and the kinetic database MOBNI5 from Thermo-Calc Software, captures reasonably well the processing pathway inducing the formation and evolution of the hierarchical microstructure, including the kinetics of $\gamma^{\prime}$ precipitation from $\gamma$ matrix and $\gamma$ precipitation from $\gamma^{\prime}$ precipitates acting as a matrix. To verify the predictive accuracy of the model, we have simulated unseen data used as a testing set. Figure 5 shows the model's performance for the radius and the volume fraction of $\gamma^{\prime}$ precipitates formed during aging treatments at 800,950 , and $1050^{\circ} \mathrm{C}$ for $500 \mathrm{~h}$. The main discrepancy related to the calculated $\gamma^{\prime}$ volume fraction, which is underestimated by $20 \%$ at the highest temperature, suggests that the equilibrium tie-lines are not perfectly estimated from the TCNI9 thermodynamic database. Despite this, the overall fair agreement between experiments and predictions encourages confidence in the model. These results make it possible to consider further guidance of the design of future advanced high-temperature HESAs using computational tools. For example, according to Chen et al. [7] the maximum strengthening contribution arising from the hierarchical microstructure is obtained with $\gamma$ particles of $3.6 \mathrm{~nm}$ in radius associated to the equilibrium volume fraction of about $8 \%$. According to the predictions, $\gamma^{\prime}$ precipitates should undergo phase separation between $950-1000 \mathrm{~K}$ for $300 \mathrm{~h}$ to achieve these optimal values for peak strength. This result suggests that tuning HESA composition to favor a higher proportion of $\gamma$ particles at the optimal size should be preferably explored as a better alternative to very long thermal aging for further improvement of the high-temperature yield strength.

Common computational thermodynamic and kinetic tools have been used to successfully rationalize the genesis and evolution of the hierarchical $\gamma-\gamma^{\prime}$ microstructure in a high entropy superalloy. The nucleation, growth, and coarsening of (i) $\gamma^{\prime}$ precipitates from supersaturated $\gamma$ during continuous cooling, and (ii) the formation of $\gamma$ particles inside supersaturated $\gamma^{\prime}$ cuboid precipitates acting as a 
supersaturated matrix during subsequent isothermal aging, were modeled separately, and the corresponding temperature-time-transformation (TTT) were simulated.

Several specific outcomes can be highlighted:

- The precipitation kinetics, the size, the morphology, the volume fraction and the number density of the $\gamma$ and $\gamma^{\prime}$ precipitates formed under isothermal and non-isothermal treatments in HESA can be predicted with a good agreement with experimental observations, which validates the use of thermodynamic and kinetic databases initially developed for Ni-based alloys.

- The simulations for the $\gamma^{\prime}$ precipitation in HESA show a shorter timescale in comparison to conventional Ni-based superalloys.

- The simulations for the $\gamma$ precipitation from $\gamma^{\prime}$ show isothermal aging performed at $1023 \mathrm{~K}$ promotes the formation of the hierarchical microstructure with features close to the peak strength. Gaining better high temperature tensile yield strength in this HESA might be achieved by lowering the aging temperature but with an increase of the aging time.

- While the development of HESAs, and more generally of HEAs, still relies mainly on the study of phase equilibria, the present work suggests that available computational thermodynamic and kinetic tools can be considered for detailed analysis and predictions of the precipitation processes. This is important to better control and optimize the microstructures and the resulting mechanical properties throughout appropriated thermal treatments and composition tuning.

\section{References}

[1] R.C. Reed, The Superalloys Fundamentals and Applications, 2006.

[2] T.K. Tsao, A.C. Yeh, C.M. Kuo, K. Kakehi, H. Murakami, J.W. Yeh, S.R. Jian, Sci. Rep. (2017).

[3] S. Chen, Q. Li, J. Zhong, F. Xing, L. Zhang, J. Alloys Compd. 791 (2019) 255-264.

[4] Y.-T. Chen, Y.-J. Chang, H. Murakami, S. Gorsse, A.-C. Yeh, Scr. Mater. 187 (2020) 177-182. 
[5] O. Senkov, D. Isheim, D. Seidman, A. Pilchak, Entropy 18 (2016) 102.

[6] D.B. Miracle, M.H. Tsai, O.N. Senkov, V. Soni, R. Banerjee, Scr. Mater. 187 (2020) 445-452.

[7] Y.T. Chen, Y.J. Chang, H. Murakami, T. Sasaki, K. Hono, Sci. Rep. (2020) 1-11.

[8] H.F. Merrick, Met. Mater Trans B 4 (1973) 885-887.

[9] J.M. Oblak, J.E. Doherty, A.F. Giamei, B.H. Kear, Met. Mater Trans B 5 (1974) 1252-1255.

[10] V. Yardley, I. Povstugar, P.P. Choi, D. Raabe, A.B. Parsa, A. Kostka, C. Somsen, A. Dlouhy, K. Neuking, E.P. George, G. Eggeler, Adv. Eng. Mater. 18 (2016) 1556-1567.

[11] S. Hata, K. Kimura, H. Gao, S. Matsumura, M. Doi, T. Moritani, J.S. Barnard, J.R. Tong, J.H. Sharp, P.A. Midgley, Adv. Mater. 20 (2008) 1905-1909.

[12] F. Vogel, N. Wanderka, Z. Balogh, M. Ibrahim, P. Stender, G. Schmitz, J. Banhart, Nat. Commun. 4 (2013).

[13] M. Senga, H. Kumagai, T. Moritani, M. Doi, Adv. Mater. Res. 26-28 (2007) 1311-1314.

[14] E. Zaiser, X.Y. Zhou, A.M. Manzoni, S. Haas, U. Glatzel, X.P. Zhang, G.B. Thompson, W. Li, F. Vogel, Acta Mater. 195 (2020) 327-340.

[15] T. Moritani, M. Ota, T. Kozakai, M. Doi, Mater. Sci. Forum 561-565 (2007) 2361-2364.

[16] J.O. Andersson, T. Helander, H. L., P.F. Shi, B. Sundman, Calphad (2002).

[17] J.S. Langer, A.J. Schwartz, J. Aerosol Sci. 11 (1980) 112.

[18] R. Kampmann, R. Wagner, in: Pergamon Press, 1984, pp. 91-103.

[19] J. Microsc. 121 (1981) 131-132.

[20] S.A. Saltikov, Stereology (1967) 163-173.

[21] M. Wen, X. Xie, H. Dong, Z. Lin, F. Wu, C.Y. Wang, J. Alloys Compd. 839 (2020) 155661.

[22] T. Hara, S. Kobayashi, T. Ueno, K. Oikawa, J. Cryst. Growth 506 (2019) 91-96.

[23] Z. Wang, O. Muránsky, H. Zhu, T. Wei, A. Sokolova, K. Short, R.N. Wright, Materialia 11 (2020) 100682.

[24] S. Onaka, N. Kobayashi, T. Fujii, M. Kato, Mater. Sci. Eng. A 347 (2003) 42-49.

[25] M.S. Chiou, A.C. Yeh, S.R. Jian, C.M. Kuo, in: Mater. Sci. Forum, Trans Tech Publications Ltd, 
2014, pp. 549-553.

[26] G. Huang, G.Q. Liu, M. Feng, M. Zhang, B. Hu, H. Wang, J. Alloys Compd. 747 (2018) 10621072. 


\section{Tables}

Table 1. Chemical compositions of HESA and different phases analyzed by APT (at.\%) [7]

\begin{tabular}{|c|c|c|c|c|c|c|c|c|c|}
\hline & Al & $\mathrm{Ti}$ & Nb & $\mathbf{N i}$ & Co & $\mathrm{Cr}$ & $\mathrm{Fe}$ & Mo & W \\
\hline Nominal & 10.2 & 5.8 & 1.2 & 48.3 & 16.9 & 7.4 & 8.9 & 0.9 & 0.4 \\
\hline \multicolumn{10}{|c|}{ After air cooling from the solvus temperature } \\
\hline Primary $\gamma^{\prime}$ & 13.1 & 8.3 & 1.3 & 56.6 & 13.2 & 2.3 & 4.5 & 0.5 & 0.2 \\
\hline Secondary $\gamma^{\prime}$ & 14.5 & 8.6 & 0.7 & 60.6 & 12.1 & 0.8 & 1.7 & 0.8 & 0.2 \\
\hline \multicolumn{10}{|c|}{ Calculated equilibrium composition of $\gamma^{\prime}$ at $1023 \mathrm{~K}$} \\
\hline Eq. $\gamma^{\prime}$ & 14.1 & 8.5 & 1.5 & 60.2 & 12.4 & 0.7 & 2.4 & 0.2 & $<0.01$ \\
\hline
\end{tabular}

\begin{tabular}{|c|c|c|c|c|c|}
\hline \multicolumn{6}{|c|}{$\begin{array}{l}\text { Table 2. Observed precipitation of } \gamma \text { inside } \gamma^{\prime} \text { after } \\
\text { isothermal aging of air cooled HESA. } N \text { stands for no } \\
\text { precipitation, } Y \text { stands for precipitation. }\end{array}$} \\
\hline \multirow[b]{2}{*}{ Temperature } & \multicolumn{5}{|c|}{ Time } \\
\hline & $10 \mathrm{~h}$ & $20 \mathrm{~h}$ & $50 \mathrm{~h}$ & $100 \mathrm{~h}$ & $200 \mathrm{~h}$ \\
\hline $1223 \mathrm{~K}$ & & $\mathrm{~N}$ & & & \\
\hline $1123 \mathrm{~K}$ & & $\mathrm{~N}$ & & & \\
\hline $1023 \mathrm{~K}$ & Y & Y & Y & Y & Y \\
\hline $923 \mathrm{~K}$ & & $\mathrm{~N}$ & & & \\
\hline $723 \mathrm{~K}$ & & $\mathrm{~N}$ & & & \\
\hline
\end{tabular}

\begin{tabular}{|c|c|c|c|c|}
\hline & 2D obser & & $3 \mathrm{D}$ equiva & \\
\hline$t$ at $1023 \mathrm{~K}$ & $r(\mathrm{~nm})$ & $\begin{array}{l}N_{A}\left(\mathrm{~m}^{-2}\right) \\
\left\{\text { per } \gamma^{\prime} \text { particles\} }\right.\end{array}$ & $R(\mathrm{~nm})$ & $N_{V}\left(\mathrm{~m}^{-3}\right)$ \\
\hline $\mathrm{Oh}$ & - & 0 & - & 0 \\
\hline $10 \mathrm{~h}$ & $2.0 \pm 1.0$ & $1.6 \pm 9.710^{15}\{30\}$ & $2.6 \pm 1.3$ & $3.2 \pm 210^{23}$ \\
\hline $20 \mathrm{~h}$ & $4.0 \pm 1.0$ & $5.2 \pm 2.410^{14}\{10\}$ & $5.1 \pm 1.3$ & $5.1 \pm 210^{22}$ \\
\hline $50 \mathrm{~h}$ & $4.5 \pm 1.0$ & $8.8 \pm 3.810^{13}\{2\}$ & $5.7 \pm 1.3$ & $7.7 \pm 410^{21}$ \\
\hline $100 \mathrm{~h}$ & $5.0 \pm 1.0$ & $1.7 \pm 0.810^{13}\{<1\}$ & $6.4 \pm 1.3$ & $1.3 \pm 0.610^{21}$ \\
\hline $200 \mathrm{~h}$ & $5.1 \pm 1.5$ & $1.4 \pm 0.610^{13}\{<1)$ & $7.0 \pm 1.9$ & $9.6 \pm 0.510^{20}$ \\
\hline
\end{tabular}




\section{Figures}

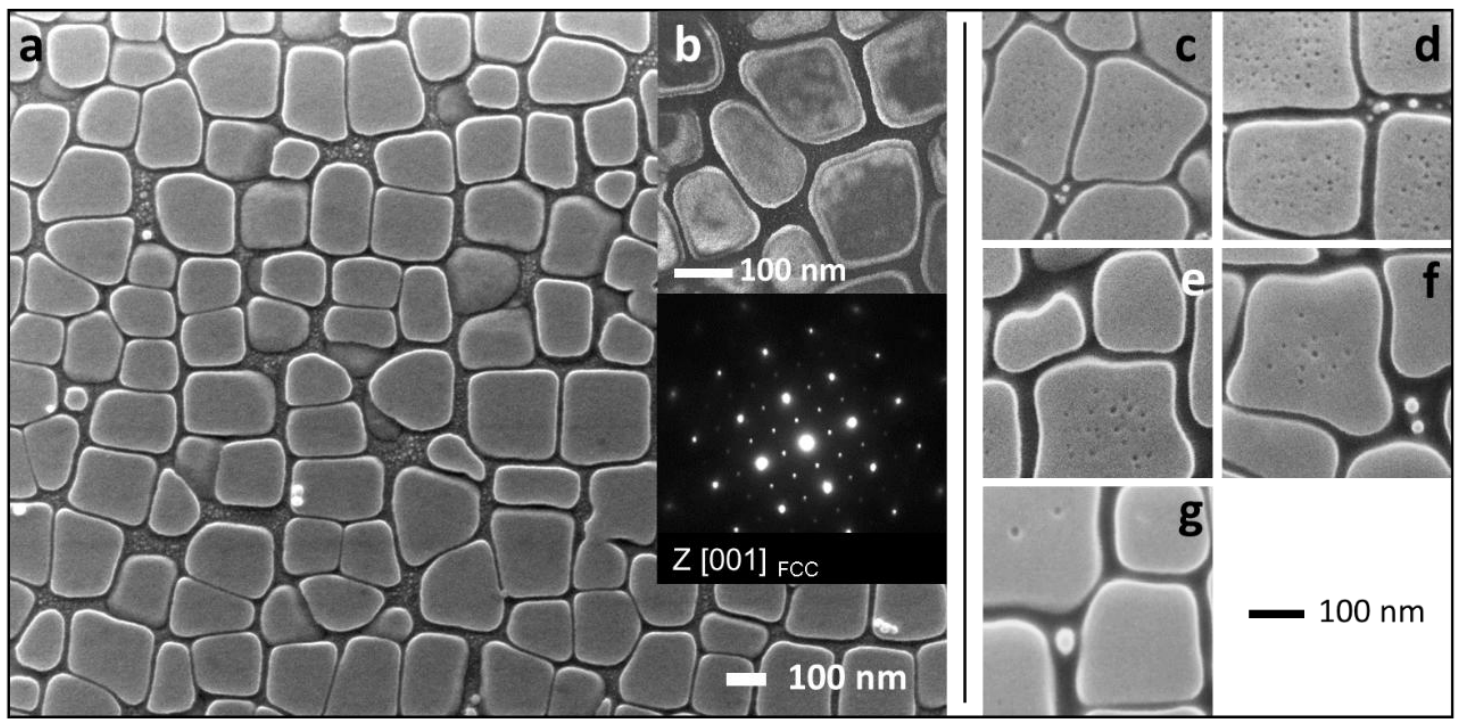

Figure 1. SEM and TEM observations of HESA after heat treatments. (a) SEM image of the

microstructure after air cooling, and TEM dark field image from ordered $\mathrm{L}_{2}(001)$ superlattice spot on [001] zone axis and the selected area electron diffraction pattern in the insets, (b)-(g) SEM images after subsequent aging at $1023 \mathrm{~K}$ for $10,20,50,100$ and $200 \mathrm{~h}$, respectively.

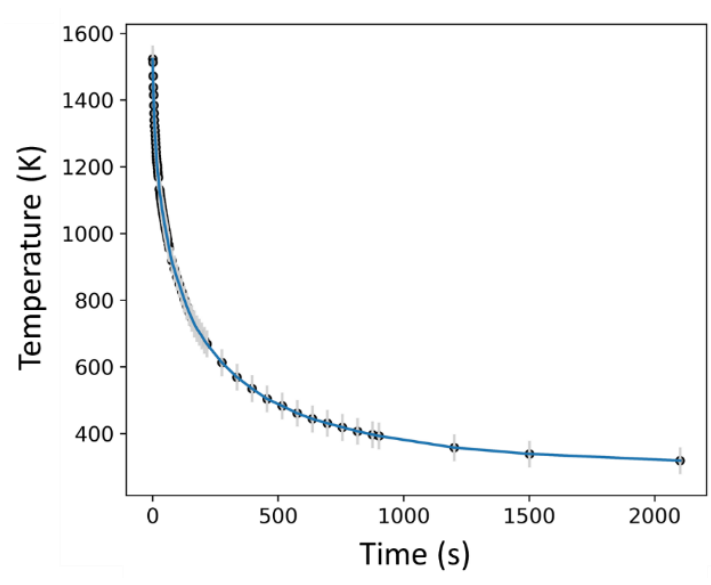

(a)

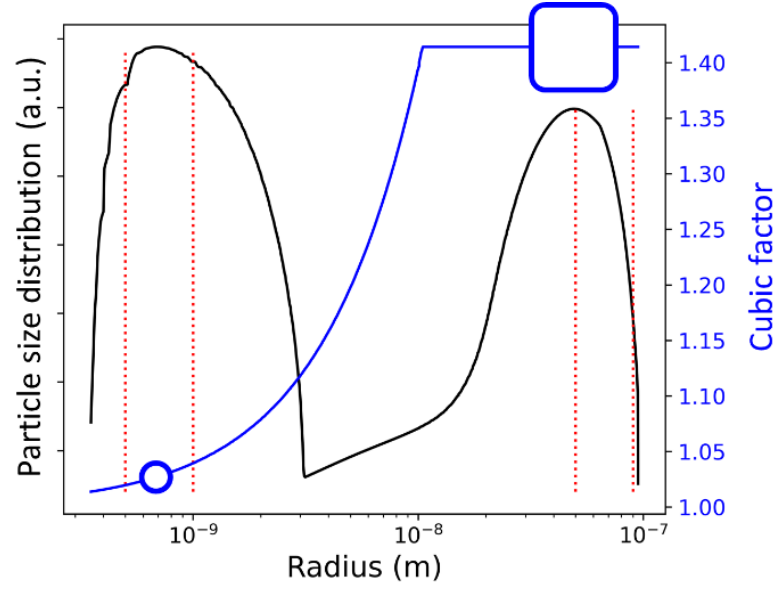

(b)

Figure 2. (a) Temperature profile measured during air cooling of the HESA sample. (b) Calculated particle size distribution and cubic factor of the $\gamma^{\prime}$ precipitates formed during continuous cooling from the solvus temperature according to the temperature profile in (a). Cubic factor ranges from 1 
for spherical shape to $\sqrt{2}$ for cubic shape [24]. Red dashed lines show the uncertainty interval for the measured radius of the primary and secondary $\gamma^{\prime}$ precipitate.

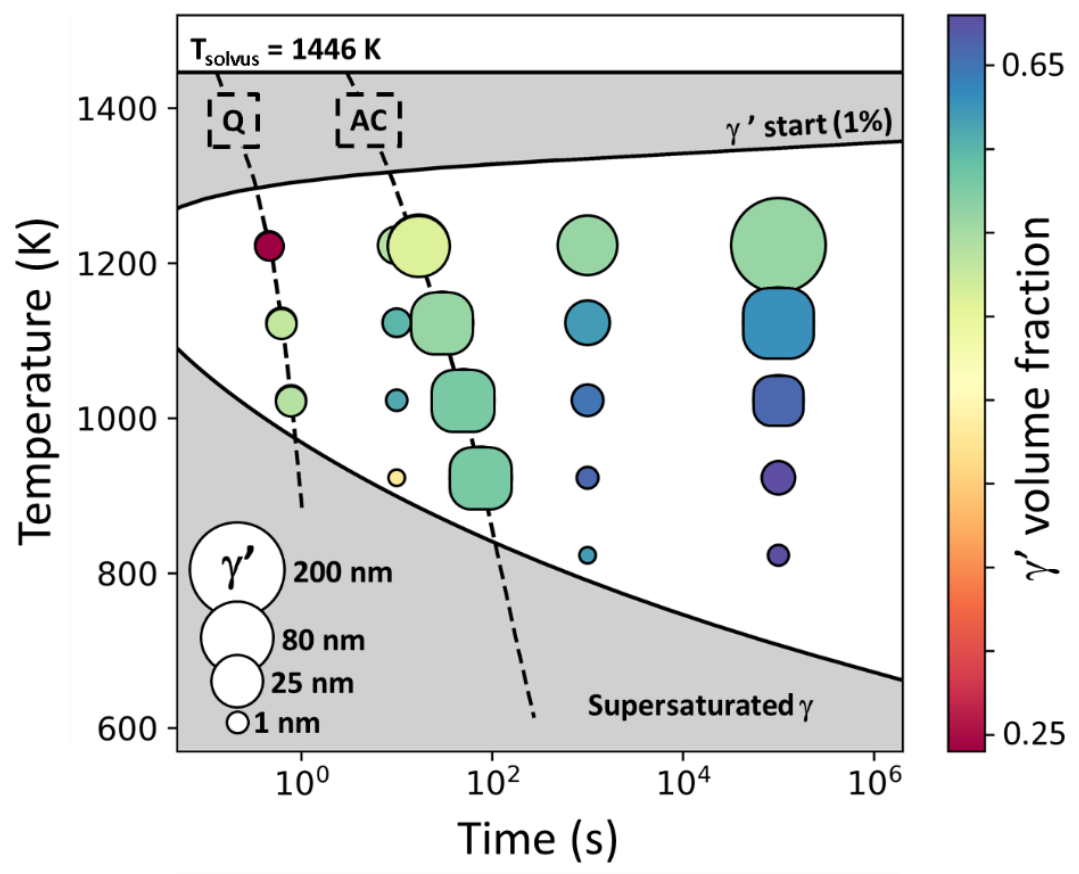

Figure 3. TTT diagram for the precipitation of $\gamma^{\prime}$ from the $\gamma$ matrix. The supersaturated $\gamma$ matrix corresponds to the gray region, while the equilibrium single-phase $\gamma$ field is shown above the horizontal solvus temperature line. The curved solid line represents temperature-time combinations calculated for a volume fraction of $1 \%$ of $\gamma^{\prime}$ ( $\gamma^{\prime}$ start curve). Inside the $\gamma^{\prime}$ start curve, circles and rounded squares show the temperature-time coordinates at which the radius, volume fraction, and morphology of $\gamma^{\prime}$ precipitates were predicted. Their radius is proportional to the calculated average radius of $\gamma^{\prime}$ precipitates, and their color indicates the calculated volume fraction $\gamma^{\prime}$ precipitates. Circles and rounded squares lying on dashed lines are calculated for non-isothermal treatments, i.e. AC stands for air cooling and $Q$ for quenching at a rate 100 times AC. 


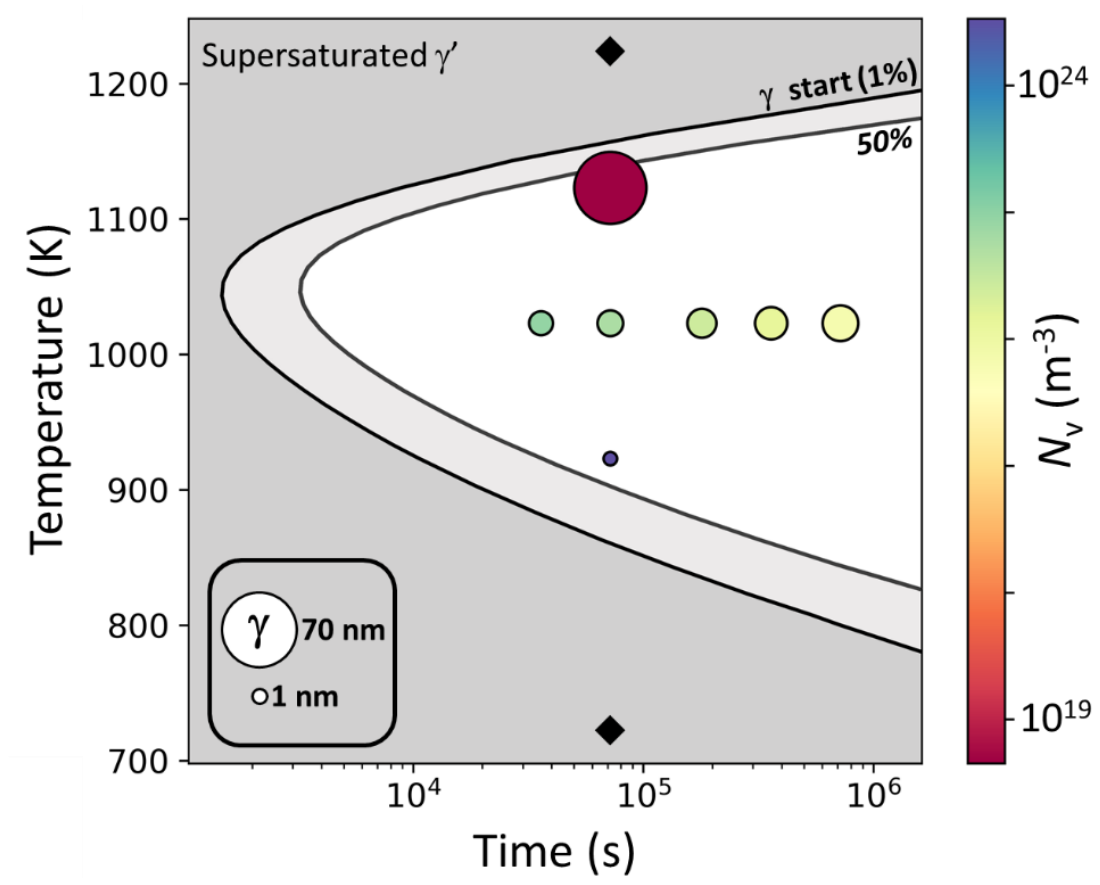

Figure 4. TTT diagram for the precipitation of $\gamma$ from $\gamma^{\prime}$ primary precipitates. The supersaturated $\gamma^{\prime}$ matrix corresponds to the gray region. The $\gamma$ start and the $50 \%$ completion curves are represented by curved solid lines. The 9 isothermal aging treatments applied to HESA after air cooling (Table 2) are shown at the corresponding temperature-time coordinates by circles when they lie inside the $\gamma$ start curve and by diamonds when they fall outside. The size of the circles is proportional to the average radius of the $\gamma$ precipitates calculated at the corresponding temperature-time coordinate, and the color indicates the calculated number density, $N_{V}$. 


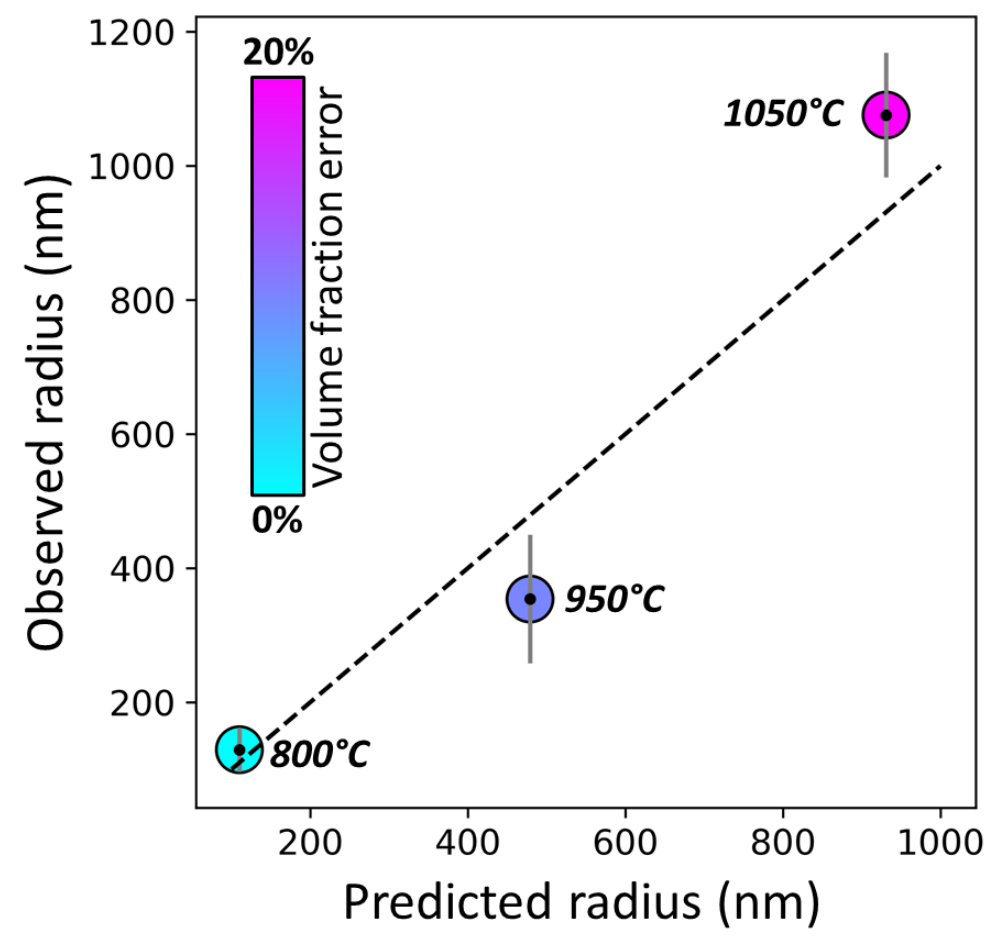

Figure 5. Observed vs predicted radius of $\gamma^{\prime}$ precipitates from $\gamma$ after thermal treatments at 800,950 , and $1050^{\circ} \mathrm{C}$ for $500 \mathrm{~h}$. The agreement between experiments and predictions for the radius is all the better the closer circles are to the dotted line. The color of the circles indicates the discrepancy between estimated and calculated values for the volume fraction of $\gamma^{\prime}$. 